\title{
Enhancing the Conceptual, Procedural and Flexible Procedural Knowledge of Pre-Service Mathematics Teachers in Algebra
}

\author{
Otun Ismaila Wasiu*, Olaoye Adetunji Abiola \\ Department of Science \& Technology Education, Faculty of Education, Lagos State University, Ojo, \\ NIGERIA \\ *Corresponding author:otun_w@yahoo.com
}

\begin{abstract}
The study investigated the effects of Solve-Reflect-Pose Strategy (SRP) on pre-service mathematics teachers' algebraic knowledge for teaching in Nigeria. A pre-test-post-test quasi experimental design was employed. Intact classes were used and in all, 182 pre-service mathematics teachers' participated in the study (92 in the experimental group taught with the SRP and 90 in the control group taught using the Modified Conventional Method (MCM). One research instrument manipulated at three levels namely: Conceptual Knowledge Test (CKT), Procedural Knowledge Test (PKT) and Flexible Procedural Knowledge Test (FPKT), was used for the quantitative data and interview protocol for qualitative data. The two research questions formulated were analysed using descriptive statistics while independent sample t-test was used to analyse the two bypotheses. Results showed that there were statistically significant differences in the mean post-test achievement scores on conceptual knowledge test, procedural knowledge test and flexible procedural knowledge test between preservice teachers exposed to the SRP and those exposed to the MCM, all in favour of the SRP group. Based on the results, SRP should be adopted as an instructional strategy and efforts should be made to integrate the philosophy of SRP into the pre-service teachers' curriculum at the teacher-preparation institutions.
\end{abstract}

Keywords: Solve-Reflect-Pose Strategy, Algebraic Knowledge for Teaching, Conceptual Knowledge, Procedural Knowledge, Flexible Procedural Knowledge

Received: $29^{\text {th }}$ June 2019, Revised: $14^{\text {th }}$ August 2019, Accepted: $14^{\text {th }}$ August 2019

\section{Introduction}

The search for new thinking and effective methods of teaching mathematical concept such as algebra has been sharpened by the abysmal achievement of students in algebraic word problems. The teaching and learning of algebra in classrooms obviously need different interactive approaches, tasks and instructional methods due to dismal performance of students in algebra (Azuka, Jekayinfa, Durojaiye, \& Okwuoza, 2013; Iji \& Uka, 2012; Salman, 2008). The mathematics teacher knowledge and skills are necessary components in the reform of teaching and learning of algebra. The possession of various structures of knowledge and skills by teachers indicates the kind of teachers they might be. 
Algebraic knowledge plays a major role in the understanding of real life situation. Despite the significant role algebra plays in the understanding of other mathematical concepts, both the students and the teachers experience difficulties in algebra more than other mathematical concepts (Boonen, Schoot, Wesel, Vries, \& Jolles, 2013). Studies have also shown that students in all age groups have experienced difficulties ranging from misconceptions on algebraic symbols as abbreviations, some experience difficulties in the use of letters in place of the unknown, some experience difficulties in forming mathematical algebraic statements that is the same with the verbal expression (Boonen et al., 2013; Khng \& Lee, 2009). Some students struggled to translate a problem usually expressed in words into algebraic notation and retranslate a solution back into word and some students' difficulties have to do with their inability to symbolize meaningful relationships within the given algebraic equations (Boonen et al., 2013; Khng \& Lee, 2009). The reasons for experiencing these difficulties in algebra might not be unconnected with methods of instruction which could involve more than simple arithmetic or algebra and mechanical use of a known algorithm (Gasco \& Villarroel, 2012; Khng \& Lee, 2009). The skills needed in solving algebra involve among others, the skills of thinking in arithmetic terms, algebraic terms, and problem solving and recently problem posing (Barwell, 2005; Nathan \& Koedinger, 2000; Dooren, Verschaffel, \& Onghena, 2015).

Experience has shown that students' difficulties and lack of understanding of algebra cannot solely be attributed to students own limitations alone. There is a general opinion that, there is a relationship between student's achievement in mathematics and teacher knowledge (Baumert et al., 2010). Some researchers are of the opinion that enhancing mathematics teachers' knowledge seems to be one of the ways of improving students' achievement in mathematics (Boonen et al., 2013). Deep understanding of algebraic concepts could involve three domains of algebraic knowledge. According to Schneider \& Stem (2010), these domains are conceptual knowledge, procedural knowledge and procedural flexibility knowledge.

Conceptual algebraic knowledge includes understanding algebraic ideas, operations and notations (Schneider \& Stem, 2010). Procedural algebraic knowledge includes choosing operations and procedures to solve algebra problems, as well as applying operations and to arrive at the correct solutions to problems (Rittle-johnson, Schneider, \& Star, 2015). Procedural flexibility knowledge includes identifying and implementing multiple methods to solve algebra problems, as well as choosing the most appropriate method (Rittle-Johnson \& Schneider, 2015; Schneider \& Stem, 2010). These domains of knowledge are essential parts of algebraic knowledge for teaching.

Teachers acquire this knowledge from teaching and other experiences outside the classroom. This knowledge influences how teachers act with students in the classroom as they engage students in studying algebra. When teachers possess these right sorts of knowledge, their interventions in the classroom lead to greater students' achievement and when teachers do not possess this sort of knowledge, their students' achievement suffer (Akinsola, 2013; Ball, Hill, \& Bass, 2005). One of the roles of a teacher's algebraic knowledge for teaching is the ability to be able to interpret and translate difficult and complex algebraic concepts to the level appropriate to the learning experiences of the students.

Teacher's method of instruction may aid or hinder the development of students' algebraic knowledge (Ake, Godino, Gonzato \& Wilhelmi, 2013). Reports from literature show that students algebraic knowledge have implications for teacher training, both in primary and secondary education (Aké, Godino, Gonzato, \& Wilhelmi, 2013; Cai \& Knuth, 2011; Carraher, 2007; Filloy, Puig, \& Rojano, 2008; Godino, Gonzato, \& Wilhelmi, 2014; Kieran, 2007; Zuya, 2015). According to Abramovich (2015), he 
considered the relationship between procedural skill and conceptual knowledge as an iterative alliance that could lead to the interpretation of problem posing as a recurrent reflection on a solved problem through the never-ending cycle "solve-reflect-pose". These researchers re-conceptualized Solve-Reflect-Pose Strategy (SRPS) as a combination of range of pedagogical approaches that are learner-centred. It is a form of cognitive-constructivist learning based on problem solving, reflective activities and problem posing strategies.

The first strategy is that, teacher engages in problem solving activities which is guided through Polya's problem solving steps. The second strategy is reflective thinking. The teacher is then guided into different methods of solutions, various students' misconceptions and errors. This would allow the teachers gain in-depth knowledge of the principle or processes underlying the given tasks. The third strategy is activities on regeneration, reformulation of similar problem. Solve-reflect-pose strategy is an active learning and teaching strategy which could enable the student to become aware of and determine his/her problem solving and posing abilities and critical thinking skills, in order to build necessary domains of knowledge, develop critical thinking skills and to perform group works (Otun, 2017).

The goal of an effective instructional method is to improve students' scores in mathematical concepts such as algebra, and this could be achieved if there is a shift from teacher-centred approach of teaching and learning of algebra. As there is dearth of literature on pre-service teachers' algebraic knowledge for teaching, these researchers decided to embark on this area of research. It becomes pertinent to look for interventions that could be manipulated in order to find their effects on pre-service teachers' algebraic knowledge for teaching. Based on this, the researchers used solvereflect-pose strategy as an instruction in teaching pre-service mathematics teachers algebraic concepts and compared it effects with modified conventional method.

Thus, the under listed research questions guided the study are (1) what is the difference in the conceptual knowledge, procedural knowledge and flexible procedural knowledge of pre-service mathematics teachers' in algebra between solve-reflect-pose approach and modified conventional method?, (2) What is the difference in the conceptual knowledge, procedural knowledge and flexible procedural knowledge of male and female pre-service mathematics teachers' in algebra between solve-reflect-pose approach and modified conventional method?

Then the following hypotheses were tested in the study (1) There is no significant difference in the conceptual knowledge, procedural knowledge and flexible procedural knowledge of pre-service mathematics teachers' in algebra between solve-reflect-pose approach and modified conventional method, (2) There is no significant difference in the conceptual knowledge, procedural knowledge and flexible procedural knowledge of male and female pre-service mathematics teachers' in algebra between solve-reflect-pose approach and modified conventional method.

\section{Research Methods}

The study employed a mixed-method approach of quantitative and qualitative methods. Using quantitative and qualitative approaches in combination provide a better understanding of research problems than using a single method. In this study, both approaches were adopted in order to provide a comprehensive analysis of the research problem. A pre-test, post-test quasi-experimental method with control group (2x2) factorial design was employed. In this design two teaching strategies (solve-reflect-pose strategy and modified conventional method) were crossed with pre-service mathematics teachers' gender (male and female). In using this design, one experimental (treatment) 
and one control group were used. Intact classes from two Colleges of Education were assigned to the experimental group and control group based on their pre-test results.

\section{Treatment Procedure}

The two groups used in this study, consisted of participants in the Experimental group $(\mathrm{E})$ that were exposed to a solve-reflect-pose intervention while the participants in the control group $(\mathrm{C})$ were treated with the lecture teaching method.

\section{Solve-reflect-pose Strategy}

Subjects in Experimental group (E) were exposed to algebraic concepts through the solve-reflect-pose strategy. The facilitator engaged the pre-service teachers in algebraic concepts tasks resulting from solve-reflect-pose group activities. In order to achieve the research objectives, the facilitator allowed the pre-service teachers to enjoy some freedom of action. The pre-service teachers chose the number of working sessions, the junior secondary school mathematics textbooks, some algebraic concepts and perceived difficult tasks to be discussed during the working sessions. During the working sessions, the facilitator guided the groups toward the achievement of conditions on the design of the solve-reflect-pose strategy flow chart. Additionally, they discussed on the solution of the tasks, discussed on students thinking and reasoning processes, discussed possible students' misconceptions, reflect on the algebraic nature of them, reflect on alternative methods of solutions and posed questions on the difficulties that pupils could face when solving the tasks.

\section{Control group}

The pre-service mathematics teachers in the control group $(\mathrm{C})$ were taught algebraic concepts with modified conventional method. The facilitator in this group followed Facilitator Instructional Guide for Modified Conventional Method to introduce the preservice teachers' to algebraic concepts and problem solving strategy. The pre-service teachers' listened; they asked the facilitator questions on area of the topic that is not clear to them and the facilitator also asked them questions.

\section{Sample and Sampling Technique}

The participants were chosen because these pre-service mathematics teachers' were assumed to have possessed appreciable knowledge of mathematics and also pedagogical skills that might have equipped them with mathematical knowledge needed for teaching at the primary and lower secondary school levels. The study involved 182 pre-service mathematics teachers' participated in the study, 92 (37 male and 55 female) in the experimental group taught with the SRP and 90 (46 male and 44 female) in the control group taught using the MCM from two colleges of education in Lagos state. These two colleges of education were purposively sampled from Lagos state of Nigeria.

\section{Research Instruments}

Algebraic Knowledge for Teaching JSS Algebra Achievement (AKTJSAAT) is one research instrument manipulated at three levels namely: Conceptual Knowledge Test $(\mathrm{CKT})$, Procedural Knowledge Test (PKT) and Flexible Procedural Knowledge Test (FPKT), was used for the quantitative data and interview protocol was used for qualitative data.

\section{Development of Algebraic Knowledge for Teaching JSS Algebra Achievement (AKTJSAAT)}

The AKTJSAAT is an hour and half test of pre-service teachers' conceptual knowledge, procedural knowledge and flexible procedural knowledge on the selected algebraic concepts used in the study. The AKTJSAAT consists of two sections A and B. Section A sought for background information of the subject. Section B comprised of 15 open-ended items presented in the form of either symbolic equations or word problems. 
It was developed by the researchers to cover all algebraic word problem expressions and equations leading to algebraic equations and simultaneous equations.

The items in the test were representative of those that can be found in most mathematics JSS text-books. The first nine items consisted of five sub-categories, which are: representing the statement mathematically, solving for the unknown, explaining or demonstrating to student who did not understand using alternative method(s) of solution, and the kind of incorrect answers that might be given to some questions by students, prediction of possible students' errors and misconceptions. These equations were presented in different word problem structures. Nine of such questions took problem structures such as 'I am thinking of two numbers'. The larger of the two numbers is less than twice the smaller number by 3. The sum of the two numbers is eighteen; 'represent the statement mathematically', 'what are the two numbers?'; 'how would you explain or demonstrate this item to a student who did not understand, using alternative method of solutions'; Another three items were presented as algebraic equations, with each instructing the pre-service teachers on formation of word problems on the given algebraic equation. These questions take problem structure such as 'Given the equation $\frac{x}{3}+\frac{4 x}{5}=8$, 'write a word problem without using add, subtract, multiply or divide. Also, do not use any variable $(a, b, c, d, \ldots \ldots . . ., x, y, z)$ to describe something in your word problem' and 'what error(s) may student(s) exhibit as they answer this question'.

The items were aligned with word problems knowledge for teaching (algebraic conceptual knowledge, algebraic procedural knowledge and algebraic flexible procedural knowledge). The responses were scored by awarding two points to each correct response of the objective item, one point to each incorrect response, and a zero for a no response. The responses were scored and the reliability coefficient of the AKTJSAAT was determined using a test-retest reliability method. It was found to be 0.76 .

\section{Interviews Schedule}

The interview protocol was designed by the researchers to collect qualitative data through in-depth interviews with the pre-service mathematics teachers. The interview schedule was made of questions which were posed to pre-service mathematics teachers in the experimental group. The questions sought for the perceptions of pre-service mathematics teachers on solve-reflect-pose strategy used for instruction, the ease of the use of the solve-reflect-pose strategy in teaching and learning of algebra and potency of solve-reflect-pose strategy on the pre-service mathematics teachers' conceptual knowledge, procedural knowledge and flexible procedural knowledge. The researchers were directly involved in the interview process to ensure consistency and uniformity of purpose.

In order to select pre-service mathematics teachers for interviews, the researcher followed the theoretical sampling strategy while analyzing pre-service mathematics teachers' answers in the test. Therefore, the researchers selected interview participants by thoroughly examining their answers to the test. In all, six pre-service mathematics teachers ( 3 male and 3 female) were selected for the interview. Data was collected using video recorder. This was done to prevent loss of information provided by the pre-service mathematics teachers.

\section{Data Collection and Analysis}

The administration of the pre-test lasted one week, and all of the pre- and post-tests contained algebraic word problems leading to linear equations in one variable and simultaneous equations of equal difficulty. After grading the pre-test, in the area of assessment, the researcher recorded how every pre-service teacher's performed in each of the sub-categories of algebraic knowledge for teaching. Treatment was then provided for 
six weeks and included review of the key algebraic areas that were assessed on the pretest.

Descriptive statistics (mean and standard deviations) and inferential tests (independent-sample t-test) were used to analyse the data after the data collected satisfied the assumptions of independent samples t-test. The differences between the experimental group and the control group for the pre- and post-tests were analysed using a t-test at 0.05 level of significant. In addition, responses from semi-structured interviews were analysed thematically to understand the perceptions of pre-service mathematics teachers on solve-reflect-pose strategy used for instruction, the ease of the use of the solve-reflect-pose strategy in teaching and learning of algebra and potency of solvereflect-pose strategy on the pre-service mathematics teachers' algebraic conceptual knowledge, procedural knowledge and flexible procedural knowledge. Audio recorded data were transcribed verbatim and transcripts were analysed using open, axial and selective coding (de Vos, 2010).

\section{Results and Discussion}

Pre-service teachers were excited when they were first introduced to solve-reflectpose (SRP) strategy and they were also curious about the strategy. The pre-test result revealed that the average score of the control group was higher than that of the experimental group. Furthermore, the significant values for the experimental group, control group and also the F-test for both data are greater than 0.05 , which means that the two data are normally distributed and homogenous.

\section{Findings Relating to Conceptual Knowledge, Procedural Knowledge and Flexible Procedural Knowledge}

Research question 1: What is the difference in the conceptual knowledge, procedural knowledge and flexible procedural knowledge of pre-service mathematics teachers' in algebra between solve-reflect-pose approach and modified conventional method?

Table 1. Mean and Standard Deviation of Pre-service Teachers' Scores in Conceptual, Procedural and Flexible Procedural Knowledge Test

\begin{tabular}{llllll}
\hline $\begin{array}{l}\text { Algebraic } \\
\text { Teaching }\end{array}$ & Knowledge & for & $\begin{array}{l}\text { Experimental } \\
\text { Group } \\
\text { N }=92\end{array}$ & Control Group \\
& & & N $=90$ & \\
& & $\begin{array}{l}\text { Pre- } \\
\text { Test }\end{array}$ & $\begin{array}{l}\text { Post- } \\
\text { Test }\end{array}$ & Pre-Test & $\begin{array}{l}\text { Post- } \\
\text { Test }\end{array}$ \\
\hline Conceptual & Mean & 25.4674 & 80.6630 & 31.5667 & 69.9556 \\
Knowledge & SD & 5.65384 & 8.59118 & 7.46083 & 17.20002 \\
Procedural Knowledge & Mean & 37.2717 & 84.5543 & 41.7556 & 70.2111 \\
& SD & 7.75745 & 7.80161 & 9.01723 & 16.51931 \\
Flexible Procedural & Mean & 42.5000 & 87.6413 & 58.9667 & 75.9778 \\
Knowledge & SD & 8.31456 & 4.80517 & 11.08339 & 9.69881 \\
\hline
\end{tabular}

Table 1 shows that the pre-service teachers in the experiment group outperformed the control group in their algebraic conceptual knowledge, procedural knowledge and flexible procedural knowledge. Specifically, the results of the pre-test of the pre-service teachers, algebraic conceptual knowledge for the experimental group performance (mean= 25.47, $\mathrm{SD}=5.65$ ) and the results for the control group (mean= 31.57, $\mathrm{SD}=$ 7.46). After teaching for eight weeks, the experimental group performance was higher (mean $=80.66, \mathrm{SD}=8.59)$ compared to that of the control group (mean=69.96, $\mathrm{SD}=$ 17.2). Moreover, in Table 1, the results of the pre-test of the pre-service teachers, 
algebraic procedural knowledge for the experimental group performance (mean $=37.27$, $\mathrm{SD}=7.76)$ and the results for the control group (mean $=41.76, \mathrm{SD}=9.02)$. The post-test result after treatment showed that the experimental group performance was higher (mean $=84.55, \mathrm{SD}=7.80$ ) compared to that of the control group (mean 70.21, SD $=16.52)$.

Furthermore, the results of the pre-test of the pre-service teachers, algebraic flexible procedural knowledge for the experimental group performance (mean $=42.50, \mathrm{SD}$ $=8.31$ ) and the results for the control group (mean $=58.97, \mathrm{SD}=11.08)$. The post-test result after treatment showed that the experimental group performance was higher (mean $=87.64, \mathrm{SD}=4.81)$ compared to that of the control group (mean $=75.81, \mathrm{SD}=$ 9.70).

Research question 2: What is the difference in the conceptual knowledge, procedural knowledge and flexible procedural knowledge of male and female pre-service mathematics teachers' in algebra between solve-reflect-pose approach and modified conventional method?

Table 2. Mean and Standard Deviation of Gender on Algebraic Knowledge for Teaching Test

\begin{tabular}{lllll}
\hline & Gender & N & Mean & SD \\
\hline \multirow{2}{*}{ post-test of CK } & Male & 83 & 73.8554 & 14.85223 \\
& Female & 99 & 76.6364 & 14.22304 \\
post-test of PK & Male & 83 & 75.2651 & 15.23161 \\
& Female & 99 & 79.3030 & 14.07883 \\
post-test of FPK & Male & 83 & 81.1446 & 9.41474 \\
& Female & 99 & 82.4848 & 9.74822 \\
\hline
\end{tabular}

It can be seen from Table 2 that there is a significant difference in the post conceptual knowledge scores test of male (Mean $=73.86, \mathrm{SD}=14.85)$ and female (mean $=76.63$, $\mathrm{SD}=14.22$ ) indicating that the mean score of the conceptual knowledge of the female pre-service mathematics teachers is greater than the mean score of the male students. There is also a significant difference in the post procedural knowledge of male preservice teachers $($ mean $=75.27, \mathrm{SD}=15.23$ ) and female (mean $=79.30, \mathrm{SD}=14.07$ ) indicating that the mean of the female pre-service mathematics teachers procedural knowledge of algebra is greater than the mean of the male pre-service mathematics teachers. Likewise, there is a significant difference in the post test flexible procedural knowledge scores test of male (mean $=81.14, \mathrm{SD}=9.41)$ and female (mean $=82.48, \mathrm{SD}$ $=9.75$ ) indicating that the mean of the female is higher than the mean of the male preservice mathematics teachers as presented in Table 2.

$\mathrm{H}_{\mathrm{O} 1}$ : There is no significant difference in the conceptual knowledge, procedural knowledge and flexible procedural knowledge of pre-service mathematics teachers' in algebra between solve-reflect-pose approach and modified conventional method.

In Table 3, it shows that there was a significant difference in the conceptual knowledge pre-service mathematics teachers' taught algebra using solve-reflect-pose strategy and those taught using modified conventional method (t-test: 5.33, $p<0.05$ ). There was a significant difference in the procedural knowledge of pre-service mathematics teachers' taught algebra using solve-reflect-pose strategy and those taught using modified conventional method (t-test: 7.52, $p<0.05$ ). Furthermore, there was a significant difference in the flexible procedural knowledge of pre-service mathematics teachers' taught algebra using solve-reflect-pose strategy and those taught using modified conventional method (t-test: $7.52, p<0.05)$. 
Table 3. Independent Samples Tests of Effects of Teaching Strategies on Post Conceptual, Procedural and Flexible Procedural Knowledge Achievement Tests

\begin{tabular}{|c|c|c|c|c|c|c|c|c|c|}
\hline \multirow{2}{*}{$\begin{array}{l}\text { Algebraic } \\
\text { Knowledge } \\
\text { for } \\
\text { Teaching }\end{array}$} & \multirow{2}{*}{$\begin{array}{l}\text { Levene's } \\
\text { Test for } \\
\text { Equality of } \\
\text { Variances }\end{array}$} & \multicolumn{8}{|c|}{ t-test for Equality of Means } \\
\hline & & & & & & & & & \\
\hline & \multirow{5}{*}{$\begin{array}{l}\text { Experimental } \\
\& \quad \text { Control } \\
\text { groups }\end{array}$} & $\mathrm{F}$ & Sig. & $\mathrm{T}$ & $\mathrm{df}$ & $\begin{array}{l}\text { Sig. } \\
(2- \\
\text { tailed }\end{array}$ & $\begin{array}{l}\text { Mean } \\
\text { Diff }\end{array}$ & $\begin{array}{l}\text { Std } \\
\text { Error } \\
\text { Diff }\end{array}$ & $\mathrm{H}_{0}$ \\
\hline Post-test of & & 87.325 & .000 & 5.330 & 180 & .000 & 10.70749 & 2.00884 & Rejected \\
\hline & & & & & & & & & \\
\hline $\begin{array}{l}\text { Post-test of } \\
\text { PK }\end{array}$ & & 61.497 & .000 & 7.51 & 180 & .000 & 14.34324 & 1.90845 & Rejected \\
\hline $\begin{array}{l}\text { Post-test of } \\
\text { FPK }\end{array}$ & & 38.703 & .000 & 10.314 & 180 & 000 & 11.66353 & 1.13089 & Rejected \\
\hline
\end{tabular}

$\mathrm{H}_{\mathrm{O} 2}$ : There is no significant difference in the conceptual knowledge, procedural knowledge and flexible procedural knowledge of male and female pre-service mathematics teachers' in algebra between solve-reflect-pose approach and modified conventional method.

Table 4. Independent Samples Tests of Effects of Gender on Post Conceptual, Procedural and Flexible Procedural Knowledge Achievement Tests

\begin{tabular}{|c|c|c|c|c|c|c|c|}
\hline & & F & Sig. & $\mathrm{t}$ & $\mathrm{df}$ & $\begin{array}{l}\text { Sig. } \\
\text { (2-tailed) }\end{array}$ & $\begin{array}{l}\text { Mean } \\
\text { Dif }\end{array}$ \\
\hline \multirow{2}{*}{$\begin{array}{l}\text { post-test of } \\
\text { CK }\end{array}$} & $\begin{array}{l}\text { Equal variances } \\
\text { assumed }\end{array}$ & .122 & .727 & -1.288 & 180 & .200 & -2.78094 \\
\hline & $\begin{array}{l}\text { Equal variances } \\
\text { not assumed }\end{array}$ & & & -1.283 & 171.66 & .201 & -2.78094 \\
\hline \multirow{2}{*}{ post-test of PK } & $\begin{array}{l}\text { Equal variances } \\
\text { assumed }\end{array}$ & .334 & .564 & -1.856 & 180 & .065 & -4.03797 \\
\hline & $\begin{array}{l}\text { Equal variances } \\
\text { not assumed }\end{array}$ & & & -1.844 & 168.99 & .067 & -4.03797 \\
\hline \multirow[t]{2}{*}{$\begin{array}{l}\text { post-test of } \\
\text { FPK }\end{array}$} & $\begin{array}{l}\text { Equal variances } \\
\text { assumed }\end{array}$ & .398 & .529 & -.938 & 180 & .349 & -1.34027 \\
\hline & $\begin{array}{l}\text { Equal variances } \\
\text { not assumed }\end{array}$ & & & -.941 & 176.41 & .348 & -1.34027 \\
\hline
\end{tabular}

Table 4 reveals that the t-value of -1.29 with $p$-value of 0.20 is greater than 0.05 level of significant using 180 degrees of freedom. The table also shows that $\mathrm{t}$-value of -1.86 with p-value of 0.07 is greater than 0.05 level of significant using 180 degrees of freedom. Furthermore, Table 4 reveals that the t-value of -0.94 with $p$-value of 0.35 is greater than 0.05 level of significant using 180 degrees of freedom. The implication of this is that, there is no statistically significant difference in the conceptual knowledge, procedural knowledge and flexible procedural knowledge of male and female pre-service 
mathematics teachers' in algebra between solve-reflect-pose approach and modified conventional method. Thus, the hypothesis of no significant difference is not rejected.

\section{Qualitative Analysis}

Results from the interview tasks conducted focused on the impact of solve-reflectpose strategy on pre-service mathematics teachers' algebraic knowledge for teaching. The results were used as lens to infer and support findings from the Algebraic Knowledge for Teaching JSS Algebra Achievement (AKTJSAAT) data. After the treatment, six out of ninety-two pre-service mathematics teachers in the experimental group were interviewed. The post-test results suggested that the majority of the pre-service mathematics teachers in the experimental group had a good mastery of algebraic knowledge for teaching. In addition, all the six mathematics pre-service teachers interviewed successfully explained the process of how they applied the solve-reflect-pose strategy to obtain the unknown in the posed tasks. Female pre-service teachers would be coded as $\mathrm{F}$ and male pre-service teachers would be coded as $\mathrm{M}$ in the conversations from the interviews.

Task: 'T'm thinking of two numbers. The larger of the two numbers is less than twice the smaller number by 3. The sum of the two numbers is 18 . What are my numbers?"

The findings show that pre-service teachers in the solve-reflect-pose strategy demonstrate greater conceptual knowledge, procedural knowledge and flexible procedural knowledge in algebra when measured as greater representation of mathematical statements, greater use of multiple and correct strategies and greater use of alternative methods of solutions was also demonstrated. All the interviewees were able to apply the solve-reflect-pose flow chart correctly. For example,

F1 stated in her interview: Now it is, of course, possible to solve this problem using only what we already know, namely, linear equations in one variable: If I call the smaller number $x$, then the larger number can be expressed as $2 x-3$ (since I'm told that the larger of the two numbers is less than twice the smaller number by 3). The other piece of information then tells us about the sum of the two numbers, namely, that $x+(2 x-3)=18$. Which can be rewritten as $3 x-3=18$ and solved to get $x=7$, therefore, the smaller number is 7 and the larger number is $2(7)-3=14-3=11$.

Some further explained the tasks using different methods of solutions. For example F2 solution: Let the two numbers be $x$ and $y$ (and let's say $x$ is the smaller of the two). Now we can translate the information from the problem into two equations

$$
\begin{aligned}
& y=2 x-3 \ldots \ldots . .(i) \\
& x+y=18 \ldots \ldots .(\text { ii })
\end{aligned}
$$

Substituting $2 x-3$ for $y$ in (ii)

$$
x+2 x-3=18
$$

$3 x=21 ; x=7$ and $y=11$. This is substitution method.

F3 solution: Let the first number $x$ and the second number be $y$

$$
\begin{aligned}
& y=2 x-3 \ldots \ldots . .(i) \\
& x+y=18 \ldots \ldots . \text { (ii) }
\end{aligned}
$$

Using elimination method, then $x=7$ and $y=11$

M4 solution: Let the two numbers be $x$ and $y$ (and let's say $x$ is the smaller of the two). Now we can translate the information from the problem into two equations

We can rewrite these equations into two line equations in general form as

$$
\begin{aligned}
& -2 x+y+3=0 \ldots . \text { (i) } \\
& x+y-18=0 \ldots \ldots \text { (ii) }
\end{aligned}
$$

Solving graphically,

Geometrically, solving two simultaneous linear equations in two unknowns means that we need to find the point(s) of intersection of two lines in the plane. (If the lines are not parallel, there will be exactly one point of intersection) The point of intersection is $x=7$ and $y=11$. 
In conclusion, the interviews revealed that all the interviewees had a good mastery of algebraic knowledge for teaching.

This study revealed that there is a differential effect of solve-reflect-post strategy and modified conventional method on algebraic conceptual knowledge, procedural knowledge and flexible procedural knowledge of pre-service mathematics teachers in algebra. The results (Tables 1) shows that the pre-service teachers exposed to solvereflect-pose approach had the higher mean score than their counterpart Modified Conventional Method group in the post-test of algebraic knowledge for teaching scores test.

The results in Table 3 show that teaching strategies (solve-reflect-pose approach and modified conventional method) are significant factors in pre-service teachers' conceptual knowledge, procedural knowledge and flexible procedural knowledge scores in algebra. The current result for algebraic conceptual, procedural and flexible procedural knowledge of the pre-service teacher is consistent with the previous findings of differential effects of student-centred teaching strategies on mathematical knowledge for teaching of pre-service mathematics teachers (Heaton, 2000; Schoenfeld, 2007; Latterell, 2008; Kastberg et al., 2012; S., Tyminski, \& Sanchez, 2013). Heaton, (2000) and Latterell (2008) in different studies found out that pre-service mathematics teachers' had knowledge that allowed them to teach traditional mathematics, but their knowledge was not deep enough to teach mathematics consistent with students-centred strategy.

According to Shulman (1987), learning to teach is complex because teachers need to know not only the subject area in depth, but how to teach the content and explain it in different ways so that diverse students can understand and demonstrate mastery. The evidence represented by pre-test points to weak algebraic conceptual knowledge, weak algebraic procedural knowledge and weak algebraic procedural flexibility knowledge of pre-service teachers as contributing factors to their weak in algebraic knowledge for teaching. During the interview section, it revealed that some of the pre-service teachers said that they had problems in representing algebraic problems mathematically. The preservice teachers struggled to transform word statements into mathematics equations in order to solve the algebraic problems, but they were not successful.

In the pre-test, it was observed that the number of pre-service teachers who gave incorrect answers to Question AKTJSAAT 1 to 8 due to failure to represent statements mathematically constitute $78 \%$ of the total number of pre-service teachers who gave incorrect answers to these questions. The pre-service teachers in the experimental group demonstrated greater scores after the treatment.

The findings in this study also revealed that pre-service mathematics teachers in the solve-reflect-pose strategy demonstrate greater conceptual knowledge, procedural knowledge and flexible procedural knowledge in algebra when measured as greater representation of mathematical statements, greater use of multiple and correct strategies and greater use of alternative methods of solutions was also demonstrated. All the interviewees were able to apply solve-reflect-pose flow chart correctly. These results were consistent with previous findings (Maciejewski \& Star, 2016; Rittle-johnson \& Star, 2009; Rittle-johnson, Star, \& Durkin, 2012). The researchers went further that the pre-service teachers appeared to know more than their results suggested and most pre-service mathematics teachers complained that they needed more time to think through their answers while some pre-service mathematics teachers suggested that they had difficulty interpreting some of the questions. Several studies have indicated that reflection through student-centred strategy can be a means by which teachers come to terms with experience (Applebaum \& Leikin, 2007; Yuretich, 2004).

In the course of this research, there was a revelation that there is no statistically significant difference in the conceptual knowledge, procedural knowledge and flexible 
procedural knowledge of male and female pre-service mathematics teachers' in algebra between solve-reflect-pose approach and modified conventional method. These findings were in line with the submissions of (Ajai \& Imoko, 2015; Hydea, 2009; Perie, M., Moran \& Lutkus, 2005) which found no difference in male and female performance after they have been exposed to a teaching strategy. However, the result is at variance with the submission of (Asante, 2014; Ogunkunle, 2007), where part of the findings showed significant gender differences.

\section{Conclusion}

Many authors have discussed the role of problem solving, reflective thinking and problem posing strategies in teaching of mathematics. Solve-reflect-pose strategy is an active learning and teaching strategy which enables the pre-service mathematics teacher to become aware of and determine his/her problem solving and posing abilities and reflective thinking skills, in order to build necessary domains of algebraic knowledge, improve in the knowledge of students' thinking processes and to perform well in problem posing tasks. This study investigated the effect of solve-reflect-pose strategy and modified conventional method on pre-service mathematics teachers' algebraic conceptual knowledge, procedural knowledge and flexible procedural knowledge. From the findings of the study, solve-reflect-pose strategy could be used effectively in a mixed gender class to teach mathematical concepts. It is recommended that mathematics teacher educators and mathematics teachers at all levels should further investigate the use of solve-reflectpose strategy as a mode of instruction in the classroom setting.

Pre-service teachers must be taught with student-centred approaches of teaching mathematics such as solve-reflect-pose strategy because this student-centred approach can be used to shape pre-service mathematics teachers' perceptions on learning and thinking and enhance their scores in mathematics. Though the study highlighted the benefits derivable from this study, the results obtained in this study showed that preservice teachers' performance is enhanced by solve-reflect-pose strategy in algebraic concepts. Further studies are recommended in order to explore the impact of solvereflect-pose strategy on other concepts in mathematics such as geometry, measurement and statistics and probability.

\section{Acknowledgement}

The authors appreciate the two colleges of education used and all the pre-service mathematics teachers who participated in this study.

\section{Bibliography}

Abramovich, S. (2015). Mathematical problem posing as a link between algorithmic thinking and conceptual knowledge. The Teaching of Mathematics, XVIII(2), 45-60.

Ajai, J. T., \& Imoko, I. L. (2015). Gender difference in mathematics achievement and retention scores: A case of problem-based learning method. International Journal of Research in Education and Scxience (IJRES), 1(1), 45-50.

Aké, L. P., Godino, J. D., Gonzato, M., \& Wilhelmi, M. R. (2013). Proto-algebraic levels of mathematical thinking. In Proceedings of the 37 th Conference of the International Group for the Psychology of Mathematics Education-PME (pp. 1-8). Kiel, Germany: Leibniz.

Akinsola, M. K. (2013). Helping Teacher Tame Underachievement in Mathematics: The Attitude Dimension. Ibadan, Nigeria: University of Ibadan.

Applebaum, M., \& Leikin, R. (2007). Looking back at the beginning: Critical thinking in solving unrealistic problems. The Mathematics Enthusiast, 4(2), 258-265.

Asante, K. O. (2014). Sex Differences in Mathematics Performance among Senior High Students in. https://doi.org/10.4314/gab.v8i2.61947 
Azuka, B. F., Jekayinfa, O., Durojaiye, D., \& Okwuoza, S. O. (2013). Difficulty Levels of Topics in the New Senior Secondary School Mathematics Curriculum as Perceived by Mathematics Teachers of Federal Unity Schools in Nigeria. Journal of Education and Practice, 4(17), 23-30.

Ball, D. L., Hill, H. C., \& Bass, H. (2005). Knowing Mathematics for Teaching. American Educator, 29, 14-22.

Barwell, R. (2005). Ambiguity in the Mathematics Classroom. Language and Education, 19(2), 118-126.

Baumert, J., Kunter, M., Blum, W., Brunner, M., Voss, T., Jordan, A., ... Tsai, Y.-M. (2010). Teachers' Mathematical Knowledge, Cognitive Activation in the Classroom, and Student Progress. American Educational Research Journal, 47(1), 133180. https://doi.org/10.3102/0002831209345157

Boonen, A. J. H., Schoot, M. Van Der, Wesel, F. Van, Vries, M. H. De, \& Jolles, J. (2013). What underlies successful word problem solving? A path analysis in sixth grade students. Contemporary Educational Psychology, 38(3), 271-279. https://doi.org/10.1016/j.cedpsych.2013.05.001

Cai, J., \& Knuth, E. (2011). Early algebraization. A global dialogue from multiple perspectives. Berlin: Springer-Verlag.

Carraher, D. W. (2007). Early algebra and algebraic reasoning. Second handbook of research on mathematics teaching and learning.

Dooren, W. Van, Verschaffel, L., \& Onghena, P. (2015). The Impact of Preservice Teachers ' Content Knowledge on Their Evaluation of Students ' Strategies for Solving Arithmetic and Algebra Word Problems. Joumal for Research in Mathematics Education, 33(5), 319-351.

Filloy, E., Puig, L., \& Rojano, T. (2008). Educational algebra. A theoretical and empirical approach. New York: Springer.

Gasco, J., \& Villarroel, J. D. (2012). Algebraic problem solving and learning strategies in compulsory secondary education. Procedia - Social and Behavioral Sciences, 46, 612616. https://doi.org/10.1016/j.sbspro.2012.05.172

Godino, J. D., Gonzato, M., \& Wilhelmi, M. R. (2014). Niveles de algebrización de la actividad matemática escolar. Implicaciones. Enseñanza de Las Ciencias, 32(1), 199-219.

Heaton, J. (2000). Secondary analysis of qualitative data: A review of the literature. York: Social Policy Research Unit (SPRU), University of York.

Hydea, J. (2009). Gender, culture, and mathematics performances. Retrieved from http/tctvido.madison.com/uw/gender

Iji, C. O., \& Uka, N. K. (2012). Influence Teachers Qualifications on Students Mathematics Scores and Interest. ABACUS: Journal of Mathematical Association of Nigeria, 37(1), 38-48.

Kastberg, S., Sanchez, W. B., Edenfield, K., Tyminski, A., Stump, S., Sanchez, W., ... Stump, S. (2012). What is the Content of Methods? Building an Understanding of Frameworks for Mathematics Methods Courses. In Proceedings for the Thirtyfourth Annual Meeting of the North American Chapter of the International Group for the Psychology of Mathematics Education. (pp. 1259-1267). Kalamazo, Michigan: Western Michigan University.

Khng, K. H., \& Lee, K. (2009). Inhibiting interference from prior knowledge : Arithmetic intrusions in algebra word problem solving. Learning and Individual Differences, 19(2), 262-268. https://doi.org/10.1016/j.lindif.2009.01.004

Kieran, C. (2007). The learning and teaching of school algebra. In D. A. Grouns (Ed.), Handbook of Research on Mathematics Teaching and Learning (pp. 390-419). New York: Macmillan..

Latterell, C. M. (2008). IUMPST: The Journal. Vol 1 (Content Knowledge), May 2008. 
The Journal, 1(May), 1-13.

Maciejewski, W., \& Star, J. R. (2016). Research in Mathematics Education Developing flexible procedural knowledge in undergraduate calculus. Research in Mathematics Education, 18(13), 229-316. https://doi.org/10.1080/14794802.2016.1148626

Nathan, M. J., \& Koedinger, K. R. (2000). Teachers' and Researchers' Beliefs About the Development. Journal For Research in Mathematics Education, 31(2), 168-190.

Ogunkunle, L. A. (2007). Effects of gender on mathematics achievement of students in constructivist and non-constructivists groups in secondary school. ABACUS, Journal of Mathematical Association of Nigeria, 32(1), 41-50.

Otun, W. I. (2017). Effects of solve-reflect-pose strategy on pre-service mathematics teachers' algebraic knowledge for teaching and problem posing skills. Lagos State University.

Perie, M., Moran, R., \& Lutkus, A. D. (2005). NAEP 2004 Trends in Academic Progress: Three Decades of Student Performance in Reading and Mathematics. U. S. Department of Education, Institute of Education Sciences, National Center for Education Statistics. Washington, DC: Government Printing Office. Retrieved from http://nces.ed.gov/ pubsearch/pubsinfo.asp?pubid=2005464

Rittle-Johnson, B., \& Schneider, M. (2015). Developing Conceptual and Procedural Knowledge of Mathematics. In In R. C. Kadosh \& A. Dowker (Eds.), Oxford bandbook of numerical cognition (pp. 1102-1118). Oxford: Oxford University Press.

Rittle-johnson, B., Schneider, M., \& Star, J. R. (2015). Not a One-Way Street: Bidirectional Relations Between Procedural and Conceptual Knowledge of Mathematics. Educational Psychology Review, 27(4), 587-597. https://doi.org/10.1007/s10648-015-9302-x

Rittle-johnson, B., \& Star, J. R. (2009). Compared to what? The effects of different comparisons on conceptual knowledge and procedural flexibility for equation solving and procedural flexibility for equation solving. Journal of Educational Psychology, 101(3), 529-554. https://doi.org/10.1037/a0014224

Rittle-johnson, B., Star, J. R., \& Durkin, K. (2012). Developing procedural flexibility : Are novices prepared to learn from comparing procedures? British Journal of Educational Psychology, 82(3), 436-455. https://doi.org/10.1111/j.20448279.2011.02037.x

Katsberg, S., Tyminski, A., \& Sanchez, W. (2013). Reframing research on methods courses in mathematics teacher education. Manuscript submitted for publication.

Salman, M. F. (2008). Analysis of errors committed in word problems involving simultaneous linear equations by Nigerian secondary school students. Ilorin Journal of Education, 2L, 126-155.

Schneider, M., \& Stem, E. (2010). The Developmental Relations Between Conceptual and Procedural Knowledge: A Multimethod Approach. Developmental Psychology, 46(1), 178-192.

Schoenfeld, A. H. (2007). The Complexities of Assessing Teacher Knowledge. Measurement: Interdisciplinary Research and Perspectives, 5(2), 198 - 204. https://doi.org/10.1080/15366360701492880

Shulman, L. S. (1987). Knowledge and Teaching: Foundations of the New Refor. Harvard Folucational Review, 57, 1-22.

Yuretich, R. F. (2004). Encouraging Critical Thinking: Measuring Skills in Large Introductory Science Classes. Journal of College Science Teaching, 33(3), 40-45.

Zuya, E. H. (2015). Mathematics Teachers' Ability to Investigate Students' Thinking Processes about Some Algebraic Concepts. Journal of Education and Practice, 5(25), 117-213. 